\title{
Research on Comprehensive Evaluation Model of Power System Priority Scheduling with Large-scale New Energy Considering Multi-base and UHVDC Transmission
}

\author{
Yiqun Liu ${ }^{1, *}$, Yuqing Wang ${ }^{1}$, Liyi Tian ${ }^{1}$, Lirong Xie ${ }^{2}$, Xin Qi ${ }^{3}$, Liu Wei ${ }^{1}$, \\ Ming Zeng ${ }^{1}$ \\ ${ }^{1}$ School of Economics and Management, North China Electric Power University, Beijing, China \\ ${ }^{2}$ Nari Technology Development Limited Company, Nanjing, China \\ ${ }^{3}$ State Grid Ningxia Electric Power Company, Yinchuan, China \\ ${ }^{*}$ Corresponding author e-mail: 280255647@qq.com
}

Keywords: Multi-base and UHVDC transmission, priority scheduling with new energy, comprehensive evaluation.

\begin{abstract}
The wind power and photovoltaic power generation is developing rapidly in China, but there are also serious problems of wind power and solar abandonment[1].In order to promote the consumption of new energy and fully realize the environmental benefits and social benefits brought by the new energy power generation, it is very important to conduct the scientific and rational evaluation of the power system priority scheduling with large-scale new energy[2].The paper first establishes a new energy priority scheduling evaluation index system based on the multi-base and UHVDC transmission factors and builds a comprehensive evaluation model of power system priority scheduling with large-scale new energy sources[3-5].Finally, the comprehensive evaluation model[68 ]is used to evaluate the new energy priority scheduling effect in three scenarios according to the actual operation data of the new energy in grids in a region of China.
\end{abstract}

\section{Introduction}

In recent years, the new energy represented by wind power and photovoltaic power generation is developing rapidly, China's wind power and photovoltaic cumulative installed capacity rank the forefront of the world and plays a significant role in optimizing the energy structure, reducing environmental pollution and achieving energy conservation. However, due to the intermittent nature and volatility nature and other characteristics of new energy power generation, there is a more serious problem of wind power and solar abandonment in some areas. Therefore, it is of great significance to carry out the evaluation of new energy priority scheduling in order to promote the energy consumption of new energy and realize the effect of new energy power generation on the environment The domestic scholars have carried out some research on the new energy priority scheduling. In the literature [9], the new energy power generation is introduced into the traditional power system economic scheduling and the mathematical model of wind power and photovoltaic output power system is established through the prediction of wind speed and light, achieving the new energy power priority scheduling in the power system. In the literature [10], a multi-energy combined power generation scheduling model for wind and water and gas combined power generation is established for power generation systems including wind farms, photovoltaic power plants, cascade hydropower stations and gas power plants. The optimal scheduling scheme is obtained by differential evolution algorithm and the validity of the scheduling method is verified. This article mainly conducts study from three aspects of the construction of new energy priority scheduling evaluation index system, the weight of the indicators and the implementation of new energy priority scheduling evaluation. 


\section{Research on evaluation index system of new energy priority scheduling}

This paper builds a large-scale new energy power system priority scheduling evaluation index system from the aspects of the operation index of new energy, and takes into account the relevant factors of multi-base and UHVDC transmission. Index system is divided into two layers, the first layer contains two main factors, respectively, the previous plan and the actual implementation of the situation, each main factor contains a number of sub-factors, as shown in Table 1.

Table 1 . New energy power system priority scheduling evaluation index system

First Grade Index

\begin{tabular}{|c|c|}
\hline \multirow{9}{*}{$\begin{array}{l}\text { Day-ahead plan } \\
\text { situation }\end{array}$} & Wind power forecasting power in peak load period \\
\hline & Maximum value of the PV forecasting \\
\hline & UHVDC channel planned power in load peak period \\
\hline & UHVDC channel planned power in load valley period \\
\hline & Day-ahead plan rotation reserve rate in load peak period \\
\hline & Wind power forecasting and planning capacity ratio \\
\hline & PV forecasting and planning capacity ratio \\
\hline & UHVDC channel plan transmission power \\
\hline & $\begin{array}{l}\text { Multi - base new energy forecasting and planning power generation } \\
\text { complementarity ratio }\end{array}$ \\
\hline \multirow{10}{*}{$\begin{array}{l}\text { Actual implementation } \\
\text { situation }\end{array}$} & Proportion of wind power generation accounts for electricity generation \\
\hline & Proportion of PV accounts for electricity generation \\
\hline & Wind power forecasting accuracy in load peak period \\
\hline & Wind power forecasting accuracy in load valley period \\
\hline & Average power of the UHVDC channel in load peak period \\
\hline & Average power of the UHVDC channel in load valley period \\
\hline & Wind power generation \\
\hline & Photovoltaic power generation \\
\hline & UHVDC channel transmission power \\
\hline & Multi - base new energy actual power generation complementarity \\
\hline
\end{tabular}

\section{Fuzzy comprehensive evaluation method for New Energy priority scheduling}

\subsection{Entropy method}

The concept of entropy was originally proposed by the French physicist K. Clausius in 1854, which was used to measure the irregularity of molecular movement in statistical physics. In 1928 Hartley first proposed the concept of classical entropy. Subsequently, the information theory widely used entropy to represent the degree of system disorder.

The entropy weight reflects the number of effective information contained in the index, and the more effective information is included in the index, the greater the entropy of the index is. The use of entropy to determine the weight of the indicators include the following three steps:

(1) Data standardization

First, to standardize the data for each index. Assuming that the $\mathrm{k}$ indexes $X_{1}, X_{2}, \ldots X_{k}$ are given, where $X_{i}=\left\{x_{1}, x_{2}, \ldots x_{n}\right\}$, it is assumed that the standardized value for each index data is $Y_{1}, Y_{2}, \ldots Y_{k}$, then $Y_{i j}=\frac{x_{i j}-\min \left(x_{i}\right)}{\max \left(x_{i}\right)-\min \left(x_{i}\right)}$.

(2) Calculate the information entropy of each index

According to the definition of information entropy in information theory, the information entropy of a set of data $E_{j}=-\ln (n)^{-1} \sum_{i=1}^{n} p_{i j} \ln p_{i j}$, where $p_{i j}=Y_{i j} / \sum_{i=1}^{n} Y_{i j}$,if $p_{i j}=0$, then definite $\lim _{p_{i j} \rightarrow 0} p_{i j} \ln p_{i j}=0$. 
(3) Determine the weight of the indexes

According to the calculation formula of information entropy, the information entropy of each index is calculated as $E_{1}, E_{2}, \ldots E_{k}$. The weight of each index is calculated by information entropy, $W_{i}=\frac{1-E_{i}}{k-\sum E_{i}}(i=1,2, \ldots, k)$.

\subsection{Fuzzy comprehensive evaluation method based on entropy weight}

There are a variety of factors must be considered in the evaluation of the merits of the scheduling plan, the absolute affiliation is difficult to accurately assess. In this paper, fuzzy mathematics theory is used to establish the fuzzy comprehensive evaluation model, and the advantages and disadvantages of the scheduling plan are evaluated synthetically. The specific evaluation steps are as follows:

(1) Set the evaluation index set and comment set

All the evaluation index constitute the evaluation index set $U$, set it to five evaluation level, that is, comment set $\mathrm{V}=$ \{worse, poor, general, good, excellent $\}$, where each comment value indicates the corresponding index or the membership of the index subset to the comment.

(2) Divide the evaluation index set

According to the index attribute, divide $U$ into $N$ subsets of indexes $U_{i}$. Assuming that each indicator subset $U_{i}$ contains $K_{i}$ indicators, that is $U_{i}=\left\{U_{i 1}, U_{i 2}, \ldots, U_{i K_{i}}\right\}$.

(3) Determine the entropy weight vector of each subset of the index

For each index subset $U_{i}$, using information entropy to determine the entropy weight of each index in the index subset $W_{j}$, then the entropy weight vector of the index subset $U_{i}$ is obtained as $A_{i}=\left[W_{1}, W_{2}, \ldots, W_{K_{i}},\right]$.

(4) First - level fuzzy comprehensive evaluation of each subset of index

According to the standard values after the standardization, the membership degree of $K_{l}$ indexes in the subgroup $U_{i}$ of the index is calculated by using the triangular membership function, and the membership degree of each comment $V_{j}=(j=1,2, \ldots, 5)$ in the comment set $\mathrm{V}$ is calculated, and the fuzzy evaluation matrix of subset is obtained as $R_{i}=\left(r_{i j}\right)_{K_{i} \times 5}$. The triangular membership function is shown in the following equation:

$$
r_{i j}\left(V_{j}\right)=\left\{\begin{array}{c}
1-r_{i, j-1}, p_{j-1} \leq x_{i j}<p_{j} \\
\frac{p_{j+1}-x_{i j}}{p_{j+1}-p_{j}}, p_{j} \leq x_{i j} \leq p_{j+1} \\
0, \quad \text { other }
\end{array}\right.
$$

where, $j=1,2, \ldots, 5, r_{i j}\left(V_{j}\right)$ is the membership of the ith indicator of the target subset $U_{i}$ on the jth comment; $P_{j}$ is the parameter corresponding to the jth comment. This article takes $p_{1}=0, p_{2}=0.25, p_{3}=0.5, p_{4}=0.75, p_{5}=1$.

The weight vector $A_{i}$ of the indicator subset $U_{i}$ is combined with the fuzzy evaluation matrix $R_{i}$ to obtain the fuzzy comprehensive evaluation result of the index subset $U_{i}$.

(5) Two - level fuzzy comprehensive evaluation of index set

The fuzzy comprehensive evaluation result of the indicator set $U$ is $B=A \circ R=A \circ\left[B_{1} ; B_{2} ; \ldots ; B_{N}\right]$, matrix $B=\left(b_{i j}\right)_{1 \times n}$ are the results of the fuzzy comprehensive evaluation of the scheduling plan.

\section{Case study}

Based on the index system of the previous construction and the fuzzy comprehensive evaluation method of the new energy priority scheduling, this paper evaluates the new energy priority scheduling by three typical days according to the actual operation data of the new energy grid in China 
Table 2 Three typical day priority scheduling evaluation index values

\begin{tabular}{|c|c|c|c|}
\hline Evaluation index & Situation 1 & Situation 2 & Situation 3 \\
\hline Wind power forecasting power in peak load period(MW) & 1460 & 1701 & 4672 \\
\hline Maximum value of the PV forecasting(MW) & 2901 & 4513 & 20455 \\
\hline UHVDC channel planned power in load peak period(MW) & 3500 & 4000 & 8000 \\
\hline UHVDC channel planned power in load valley period(MW) & 2500 & 2800 & 3500 \\
\hline Day-ahead plan rotation reserve rate in load peak period (\%) & 56.34 & 60.93 & 118.65 \\
\hline $\begin{array}{l}\text { Day-ahead plan wind power accepted power in load peak } \\
\text { period(MW) }\end{array}$ & 1440 & 1681 & 4477 \\
\hline PV forecasting and planning capacity ratio & 8.41 & 8.65 & 48.07 \\
\hline UHVDC channel plan transmission power(MWh) & 50000 & 63000 & 80000 \\
\hline $\begin{array}{c}\text { Multi - base new energy forecasting and planning power } \\
\text { generation complementarity ratio }\end{array}$ & 2.68 & 2.56 & 5.66 \\
\hline $\begin{array}{l}\text { Proportion of wind power generation accounts for electricity } \\
\text { generation }(\%)\end{array}$ & 6.63 & 9.09 & 27.45 \\
\hline Proportion of PV accounts for electricity generation (\%) & 5.02 & 6.17 & 3.71 \\
\hline Wind power forecasting accuracy in load peak period (\%) & 70 & 84 & 82 \\
\hline Wind power forecasting accuracy in load valley period $(\%)$ & 31 & 91 & 77 \\
\hline $\begin{array}{l}\text { Average power of the UHVDC channel in load peak } \\
\text { period(MW) }\end{array}$ & 4064 & 4071 & 5758 \\
\hline $\begin{array}{l}\text { Average power of the UHVDC channel in load valley } \\
\text { period(MW) }\end{array}$ & 4064 & 4065 & 4068 \\
\hline Wind power generation(MWh) & 17854 & 25376 & 76575 \\
\hline Photovoltaic power generation(MWh) & 13514 & 17291 & 10351 \\
\hline UHVDC channel transmission power(MWh) & 85599 & 86404 & 86386 \\
\hline $\begin{array}{c}\text { Multi - base new energy actual power generation } \\
\text { complementarity }(\%)\end{array}$ & 8.65 & 7.89 & 6.09 \\
\hline
\end{tabular}

Based on the indicator values, the steps for the comprehensive evaluation of case 1 are as follows:

According to the new energy priority scheduling evaluation index system, the index is divided into two indicators of the subset, that is, the day-ahead plan situation indexes and the actual implementation situation indicators. Using the entropy weight method to determine the weight of each subset of the indicators are:
$A_{1}=\left[\begin{array}{llll}0.12 & 0.11 & 0.11 & 0.08\end{array}\right.$
$\left.\begin{array}{lllll}0.12 & 0.12 & 0.15 & 0.07 & 0.13\end{array}\right]$
$A_{2}=\left[\begin{array}{llll}0.13 & 0.08 & 0.07 & 0.07\end{array}\right.$
0.19
0.10
0.130 .08
$\left.\begin{array}{ll}0.07 & 0.07\end{array}\right]$

Using the triangular membership function, the fuzzy evaluation results of each subset of indicators are obtained as follows:

$$
\begin{aligned}
& R_{1}=\left[\begin{array}{lllll}
0.98 & 0.02 & 0 & 0 & 0
\end{array}\right] \\
& R_{2}=\left[\begin{array}{lllll}
0.77 & 0.01 & 0.14 & 0.01 & 0
\end{array}\right]
\end{aligned}
$$

Assuming that the weight vector of the two indicator subsets is $(0.40 .6)$ for the planned and actual implementation, the fuzzy comprehensive evaluation of situation 1 can be obtained as follows:

$$
B=\left[\begin{array}{lllll}
0.85 & 0.02 & 0.08 & 0.01 & 0.04
\end{array}\right]
$$

Similarly, the results of fuzzy comprehensive evaluation of situations 2 and 3 can be obtained, as shown in Table 3. 
Table 3 Results of three situations of fuzzy comprehensive evaluation

\begin{tabular}{|c|c|c|c|c|c|}
\hline Scheduling plan & Worse & Poor & General & Good & Excellent \\
\hline Situation1 & 0.85 & 0.02 & 0.08 & 0.01 & 0.04 \\
\hline Situation 2 & 0.45 & 0.25 & 0.03 & 0.04 & 0.23 \\
\hline Situation 3 & 0.14 & 0 & 0 & 0.07 & 0.79 \\
\hline
\end{tabular}

In the above three situations, the maximum value of the PV forecasting, the day-ahead plan rotation reserve rate in load peak period, the UHVDC channel transmission power, and the proportion of wind power generation accounts for electricity generation and other indicators in the situation 1 are much lower than those in the situation 3. And the corresponding index in situation 2 is higher than that in situation 1. Therefore, according to the result of fuzzy comprehensive evaluation and the principle of maximum membership degree, the final comment of situation 1 and situation 2 is "worse", but case 2 is better than case 1 . The final review of situation 3 is "excellent", and the new energy priority scheduling situation for the three situations is given as Situation 3> Situation 2> Situation 1.

\section{Conclusion}

Based on the multi-base and UHVDC transmission factors, this paper establishes a new energy priority scheduling evaluation index system and builds a comprehensive evaluation model of power system priority scheduling with large-scale new energy, using the comprehensive evaluation model to evaluate the effect of new energy priority scheduling in three scenarios based on the actual operation data of new energy in China's regional power grid. Based on the results of the entropy method, the index of the wind power forecasting power, the wind power forecasting power in peak load period, the PV forecasting and planning capacity ratio, the proportion of wind power generation accounts for electricity generation and the average power of the UHVDC channel in load peak period have a larger impact on the new energy priority scheduling. Therefore, in the new energy priority scheduling, the focus should be the above indexes. According to the nature of these indicators, optimize the new energy priority scheduling effect by changing the index value in the scheduling plan.

\section{Acknowledgments}

This work was financially supported by the Science and Technology Project of SGCC (SGNX0000DKJS1600128).

\section{References}

[1] Q. Zhou, N. B. Wang, L. Ran, Cause Analysis on Wind and Photovoltaic Energy Curtailment and Prospect Research in Chin [J]. Electric Power,2016, 49(9):7-12.

[2] Y. Wang. Research and application of new energy power generation prior scheduling evaluation technology[D]. North China Electric Power University (BeiJing), 2016.

[3] S. OuYang, Y. L. Shi, A New Improved Entropy Method and Its Application in Power Quality Evaluation[J]. Automation of Electric Power Systems, 2013, 37(21):156-159.

[4] X. Y. Yang, H. Liu, B. Zhang, A Combination Method for Photovoltaic Power Forecasting Based on Entropy Weight Method [J]. Acta Energiae Solaris Sinica, 2014, 35(5):744-749.

[5] Song B W, Pan G, Yu li H U, et al. Fuzzy AHP of Torpedo System Based on Entropy Weight[J]. Systems Engineering-theory \& Practice, 2001.

[6] W. Zhao. The Risk Evaluation Research of Grid Connected Photovoltaic Power Generation Project Based on Multi-level Fuzzy Comprehensive Evaluation Method[D]. Southeast University, 2016.

[7] Jin J L, Wei Y M, Ding J. Fuzzy comprehensive evaluation model based on improved analytic hierarchy process[J]. Journal of Hydraulic Engineering, 2004(2):144-147.

[8] K. Pan. Cordination Optimization Dispatch and Its Evaluation in Wind Integrated Power Systems[D]. Huazhong University of Science and Technology, 2014. 
[9] G. Jia. Economic Dispatch of New Energy Integrated Power System[D]. Taiyuan University of Technology, 2014.

[10] T. Q. Chen. A Joint Optimal Dispatching Method of Wind-Photovoltaic-Hydro-Gas Generation System[D]. North China Electric Power University (BeiJing), 2015 